\title{
Effects of organic solvents on two retinal pigment epithelial lipofuscin fluorophores, A2E and all-trans-retinal dimer*
}

\author{
Qiu-xia JIN ${ }^{\S 1}$, Xin-ran $\mathrm{DONG}^{\S 2}$, Jing-meng $\mathrm{CHEN}^{3}, \mathrm{Ke} \mathrm{YAO}^{2}$, Ya-lin $\mathrm{WU}^{\dagger 11,2}$ \\ $\left({ }^{1}\right.$ College of Pharmaceutical Sciences, Zhejiang University, Hangzhou 310058, China) \\ ( ${ }^{2}$ Eye Center, the Second Affiliated Hospital, School of Medicine, Zhejiang University, Hangzhou 310009, China) \\ ( ${ }^{3}$ School of Medicine, Zhejiang University City College, Hangzhou 310015, China) \\ †E-mail: yalinw@zju.edu.cn
}

Received July 19, 2013; Revision accepted Nov. 7, 2013; Crosschecked May 7, 2014

\begin{abstract}
Gene and drug therapies are being developed to alleviate vision loss in patients with Stargardt's disease and age-related macular degeneration (AMD). To evaluate the therapeutic effects of these treatments, organic solvents are routinely used to extract and quantify bisretinoid lipofuscin constituents, such as $N$-retinylidene- $N$-retinylethanolamine (A2E) and all-trans-retinal dimer (ATR-dimer). By high-performance liquid chromatography (HPLC), we found that A2E and ATR-dimer were both altered by tetrahydrofuran (THF) and chloroform, but were stable in dimethyl sulfoxide (DMSO) or methanol ( $\mathrm{MeOH}$ ). In addition, cyclohexane and ethanol (EtOH) did not alter ATR-dimer, whereas an alteration of A2E occurred in EtOH. On the basis of these findings, we designed processes II-IV, generated by modifications of process I, a routine method to measure bisretinoid compounds in vivo. Extra amounts of either ATR-dimer or A2E in mouse eyecups were released by processes II-IV versus process I. Efforts to clarify the effects of organic solvents on lipofuscin pigments are important because such studies can guide the handling of these fluorophores in related experiments.
\end{abstract}

Key words: $N$-retinylidene- $N$-retinyl-ethanolamine (A2E), All-trans-retinal dimer, Lipofuscin, Organic solvents, Retinal pigment epithelial doi: 10.1631 /jzus.B1300194

Document code: A

CLC number: R774.5

\section{Introduction}

Fluorescent bisretinoids accumulate as lipofuscin in retinal pigment epithelial (RPE) cells of the eye in an age-dependent manner, and are considered to be implicated in the pathogenesis of Stargardt's disease (Shroyer et al., 1999; Weng et al., 1999) and agerelated macular degeneration (AMD) (Sparrow and Boulton, 2005). These fluorophores are derived from random reactions of all-trans-retinal (ATR), the ret-

\footnotetext{
${ }^{\ddagger}$ Corresponding author

${ }^{\S}$ The two authors contributed equally to this work

* Project supported by the National Natural Science Foundation of China (Nos. 21202146 and 81271018), the Fundamental Research Funds for the Central Universities, the Zhejiang Scientific Research Foundation for the Returned Overseas Chinese Scholars (No. J20120556), and the Zhejiang Key Laboratory Fund of China (No. 2011E10006)

(c) Zhejiang University and Springer-Verlag Berlin Heidelberg 2014
}

inoid that is generated from a photon of lightmediated isomerization of 11-cis-retinal, the inherent chromophore of visual pigment (rhodopsin). Currently, at least nine bisretinoid constituents have been identified in RPE lipofuscin, including $N$-retinylidene$N$-retinyl-ethanolamine (A2E) (Fig. 1a), isoA2E, $N$-retinylidene- $N$-retinyl-phosphatidylethanolamine (A2PE), $\quad N$-retinylidene- $N$-retinyl-glycerophosphoethanolamine (A2-GPE), $N$-retinylidene- $N$-retinyldihydropyridine-phosphatidylethanolamine (A2DHP-PE), $N$-retinylidene- $N$-retinyl-dihydropyridineethanolamine (A2-DHP-E), all-trans-retinal dimer (ATR-dimer) (Fig. 1b), all-trans-retinal dimerphosphatidylethanolamine (ATR-dimer-PE) (Fig. 1c), and all-trans-retinal dimer-ethanolamine (ATRdimer-E) (Fig. 1d) (Parish et al., 1998; Ben-Shabat et al., 2002; Yamamoto et al., 2011; Wu et al., 2013). The non-enzymatic biosynthetic pathways leading to 
(a)

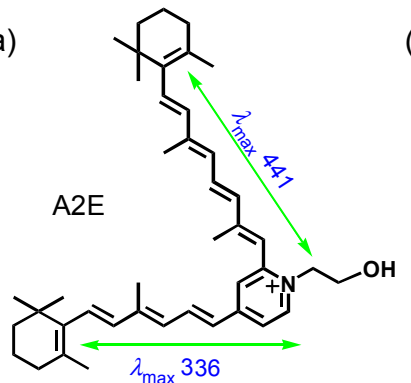

(b)

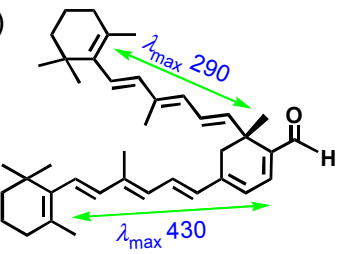

ATR-dimer (c)

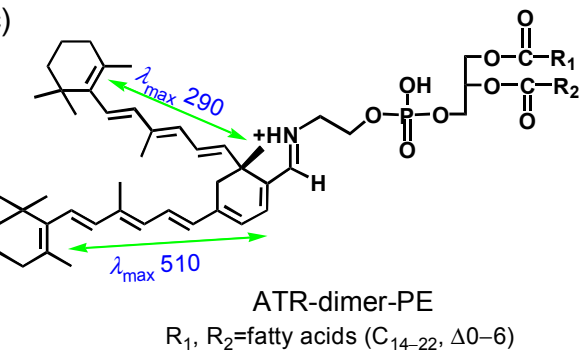

(d)

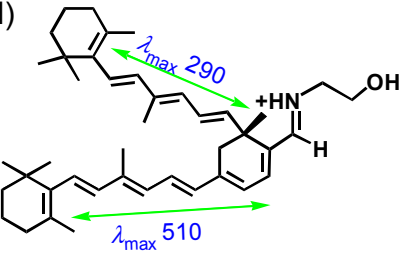

ATR-dimer-E
Fig. 1 Some bisretinoid compounds associated with the formation of retinal pigment epithelial (RPE) lipofuscin Structures, UV-visible absorbance (nm) and electronic transition assignments $(\leftrightarrow)$ are shown. (a) A2E; (b) ATR-dimer; (c) ATR-dimer-PE; (d) ATR-dimer-E the formation of A2E and ATR-dimer have, at least in part, been elucidated, and for these two molecules, biogenesis begins in photoreceptor cells (Liu et al., 2000; Ben-Shabat et al., 2002; Fishkin et al., 2005). When discarded photoreceptor outer segments are phagocytosed by RPE cells, the bisretinoid precursors are deposited into the lysosomal compartment of the cells where phospholipase-D activity can remove phosphatidic acid from $\mathrm{A} 2 \mathrm{PE}$ to release $\mathrm{A} 2 \mathrm{E}$ and from ATR-dimer-PE to yield ATR-dimer-E (Ben-Shabat et al., 2002; Kim et al., 2007; Sparrow et al., 2008; Wu et al., 2013). Evidence from several fronts indicates that excessive accumulation of $\mathrm{A} 2 \mathrm{E}$ in vitro can mediate detergent-like effects on cell membranes (Sparrow et al., 1999), and lead to the alkalinization of lysosomes (Holz et al., 1999) and detachment of pro-apoptotic proteins from mitochondria (Suter et al., 2000). In addition, illumination of A2E-laden RPE cells with blue light can damage DNA in RPE cells and cause RPE cell death (Sparrow et al., 2000; 2003). By comparison with A2E, not only is ATR-dimer a more efficient generator of singlet oxygen, but the aldehyde-containing pigment is more reactive with singlet oxygen (Kim et al., 2007). Inadvertent amassing of lipofuscin granules in RPE cells is not a feature of cell aging alone. Remarkably, excessive amounts of these pigments are also present in RPE cells of people with some inherited retinal disorders caused by mutations in ABCA4 (Allikmets et al., 1997), the gene that encodes a photoreceptorspecific adenosine triphosphate (ATP)-binding cassette transporter (Sun et al., 1999; Ahn et al., 2000). These $A B C A 4$-related retinal disorders include Stargardt's disease, retinitis pigmentosa, and cone-rod dystrophy (Shroyer et al., 1999; Weng et al., 1999; Wu et al., 2010). Elevated lipofuscin levels also feature in mouse models that mimic ELOVL4-related autosomal dominant macular dystrophy (Vasireddy et al., 2009) and deficiencies in members of the retinol dehydrogenase family of enzymes (Maeda et al., 2007; Chrispell et al., 2009). On the other hand, although A2E was harmful to RPE cells at high concentrations or when oxidized, its phototoxic properties were determined to be insignificant compared to those of ATR (Wielgus et al., 2010). Accordingly, the endogenous production of A2E likely functions as a mechanism by which the retina is protected against damage elicited by ATR.

In this work, our aim was to investigate the effects of organic solvents on A2E and ATR-dimer. A subordinate goal was to establish proper processes by which these two adducts are obtained and quantified by high-performance liquid chromatography (HPLC).

\section{Materials and methods}

\subsection{Animals}

C57BL/6 mice were purchased from the Shanghai SLAC Laboratory Animal Co., Ltd., China, and raised under 12-h on-off cyclic lighting with an in-cage illuminance of $65 \mathrm{~lx}$. 


\subsection{Syntheses of A2E and ATR-dimer}

One-step biomimetic preparation of A2E was carried out according to the procedure of Parish et al. (1998). ATR-dimer was synthesized from two molecules of ATR in the presence of sodium hydride as published (Fishkin et al., 2005).

\subsection{Incubation of pigments in organic solvents}

Each pigment was dissolved in dimethyl sulfoxide (DMSO) to make a $10 \mathrm{mmol} / \mathrm{L}$ stock solution in $3.7 \mathrm{ml}$ amber glass threaded vials. Final solutions $(300 \mu \mathrm{mol} / \mathrm{L})$ were generated by dilution of $15 \mu 1$ of stock solutions with $485 \mu 1$ DMSO, tetrahydrofuran (THF), cyclohexane, chloroform, methanol $(\mathrm{MeOH})$ or ethanol (EtOH). Incubation time was set at $0,1,3$, 5 , and $12 \mathrm{~h}$. All operations were performed under dim red light at room temperature.

\subsection{HPLC quantification}

Samples $(30 \mu 1)$ were subjected to HPLC using an Alliance System (Waters Corp., Milford, MA, USA) equipped with a 2695 separation module, a 2998 photodiode array detector, and a 2475 multi- $\lambda$ fluorescence detector. For compound elution, an Atlantis $\mathrm{dC} 18(3 \mu \mathrm{m}, 4.6 \mathrm{~mm} \times 150 \mathrm{~mm})$ reverse phase column was used for the stationary phase, and a gradient of acetonitrile in water with $0.1 \%$ trifluoroacetic acid (TFA) was set for the mobile phase: $85 \%-100 \%$ acetonitrile, $0.8 \mathrm{ml} / \mathrm{min}$ for $15 \mathrm{~min} ; 100 \%$ acetonitrile, $0.8-1.2 \mathrm{ml} / \mathrm{min}$ for $15-20 \mathrm{~min}$; and, $100 \%$ acetonitrile $1.2 \mathrm{ml} / \mathrm{min}$ for $20-40 \mathrm{~min}$. Detection by photodiode array was set at a wavelength of $430 \mathrm{~nm}$. Integrated peak areas $(\mu \mathrm{V} \cdot \mathrm{s})$ were determined using Empower ${ }^{\mathbb{B}} 3$ software.

\subsection{Pigment extraction and HPLC analysis}

To measure toxic lipofuscin pigments in the wild-type mouse eyecups, four processes were designed. Process I: tissues were homogenized in a $\mathrm{v} / \mathrm{v}$ solution of phosphate buffered saline (PBS) and 50\% methanol chloroform using a $7 \mathrm{ml}$-scale glass tissue grinder, then transferred to a $15-\mathrm{ml}$ conical centrifuge tube. Following centrifugation at $4000 \times g$ for $5 \mathrm{~min}$, the organic layer was placed in a $25-\mathrm{ml}$ round-bottom flask. Residues were collected from three consecutive chloroform extractions. After removal of the combined solvents in a rotary evaporator, the residual material was transferred into a $0.5-\mathrm{ml}$ centrifuge tube with $50 \%$ methanolic chloroform, and dried under argon gas. The resulting extract was re-dissolved in $50 \%$ methanolic chloroform, and centrifuged at $7500 \times \mathrm{g}$ for $1 \mathrm{~min}$. The supernatant was examined by HPLC. Process II: by comparison with process I, the minor modification was that the resulting extract was re-dissolved in cyclohexane. Process III: the minor difference from process I was that the resulting extract was re-dissolved in $\mathrm{MeOH}$. Process IV: tissues were homogenized in $\mathrm{MeOH}$ using a 7 ml-scale glass tissue grinder, and transferred to a $15-\mathrm{ml}$ conical centrifuge tube. After centrifugation at $4000 \times g$ for $5 \mathrm{~min}$, the organic layer was placed in a $25-\mathrm{ml}$ round-bottom flask. Residues were collected from three consecutive $\mathrm{MeOH}$ extractions. After removal of the combined solvents in a rotary evaporator, this residual material was transferred into a $0.5-\mathrm{ml}$ centrifuge tube with addition of $\mathrm{MeOH}$, and dried under argon gas. The resulting extract was re-dissolved in $\mathrm{MeOH}$ and centrifuged at $7500 \times \mathrm{g}$ for $1 \mathrm{~min}$. The $50 \mu 1$ of supernatant was monitored by HPLC. Posterior eyecups (4-6 eyes/sample) harvested from C57BL/6 mice ( 8 months old) were pooled, and the molecules were obtained and quantified based on processes I-IV. For chromatographic separation, an analytical scale Atlantis dC18 $(3 \mu \mathrm{m}, 4.6 \mathrm{~mm} \times 150 \mathrm{~mm})$ column was used with a gradient mobile phase consisting of acetonitrile and water in the presence of 0.1\% TFA: $75 \%-90 \%$ acetonitrile (0-30 $\mathrm{min}), 90 \%-$ $100 \%$ acetonitrile (30-40 $\mathrm{min}$ ), and $100 \%$ acetonitrile (40-100 $\mathrm{min}$ ) with a flow rate of $0.5 \mathrm{ml} / \mathrm{min}$. Photodiode array detection was monitored at $430 \mathrm{~nm}$. Extraction and injection for HPLC were carried out under dim red light. Integrated peak areas $(\mu \mathrm{V} \cdot \mathrm{s})$ were determined using Empower ${ }^{\mathbb{B}} 3$ software.

\subsection{Statistical analysis}

Data were analyzed by one-way analysis of variance (ANOVA) and Newman-Keul multiple comparison tests (Prism 4, GraphPad Software, San Diego, CA, USA).

\section{Results}

\subsection{Effects of organic solvents on pigments}

Given that DMSO was used to make stock solutions of bisretinoid molecules, we first incubated either A2E or ATR-dimer in DMSO for 0-12 h. As 
depicted in Figs. 2a-2e and Figs. 3a-3e, A2E and ATR-dimer were stable in DMSO on the basis of the height and shape of the peaks in the HPLC chromatograms. Owing to the poor solubility of A2E in cyclohexane, we excluded the case for this nonpolar organic solvent and incubated A2E in THF, chloroform, $\mathrm{MeOH}$, and $\mathrm{EtOH}$ for $0-12 \mathrm{~h}$. The resulting solutions were analyzed by HPLC. The data showed that $\mathrm{MeOH}$ did not affect A2E (Figs. 4a-4e), while THF, chloroform, and EtOH obviously altered A2E when mixed (Figs. $2 \mathrm{f}-2 \mathrm{o}$ and $4 \mathrm{~g}-4 \mathrm{k}$ ). Incubation of A2E in THF resulted in the release of peaks $1\left(\lambda_{\max }\right.$, 330 and $420 \mathrm{~nm})$ and $2\left(\lambda_{\max }, 330\right.$ and $\left.425 \mathrm{~nm}\right)$, and treatment of A2E with chloroform yielded peak 3 , absorbing at 336 and $433 \mathrm{~nm}$ (Fig. 5). All of these newly generated peaks were eluted much earlier than the A2E peak in the HPLC chromatograms, indicating that components attributable to peaks $1-3$ were more hydrophilic than the parent compound (Figs. 2f-2o). In the case of ATR-dimer, it was mixed with THF, cyclohexane, chloroform, $\mathrm{MeOH}$, and $\mathrm{EtOH}$ for $0-12 \mathrm{~h}$. HPLC analysis of these solutions showed that adverse solvent effects on this fluorophore were not observed in cyclohexane, $\mathrm{MeOH}$, or EtOH (Figs. 3k-3o and 6), whereas ATR-dimer was obviously altered when either THF (Figs. 3f-3j) or chloroform (Figs. 3p-3t)
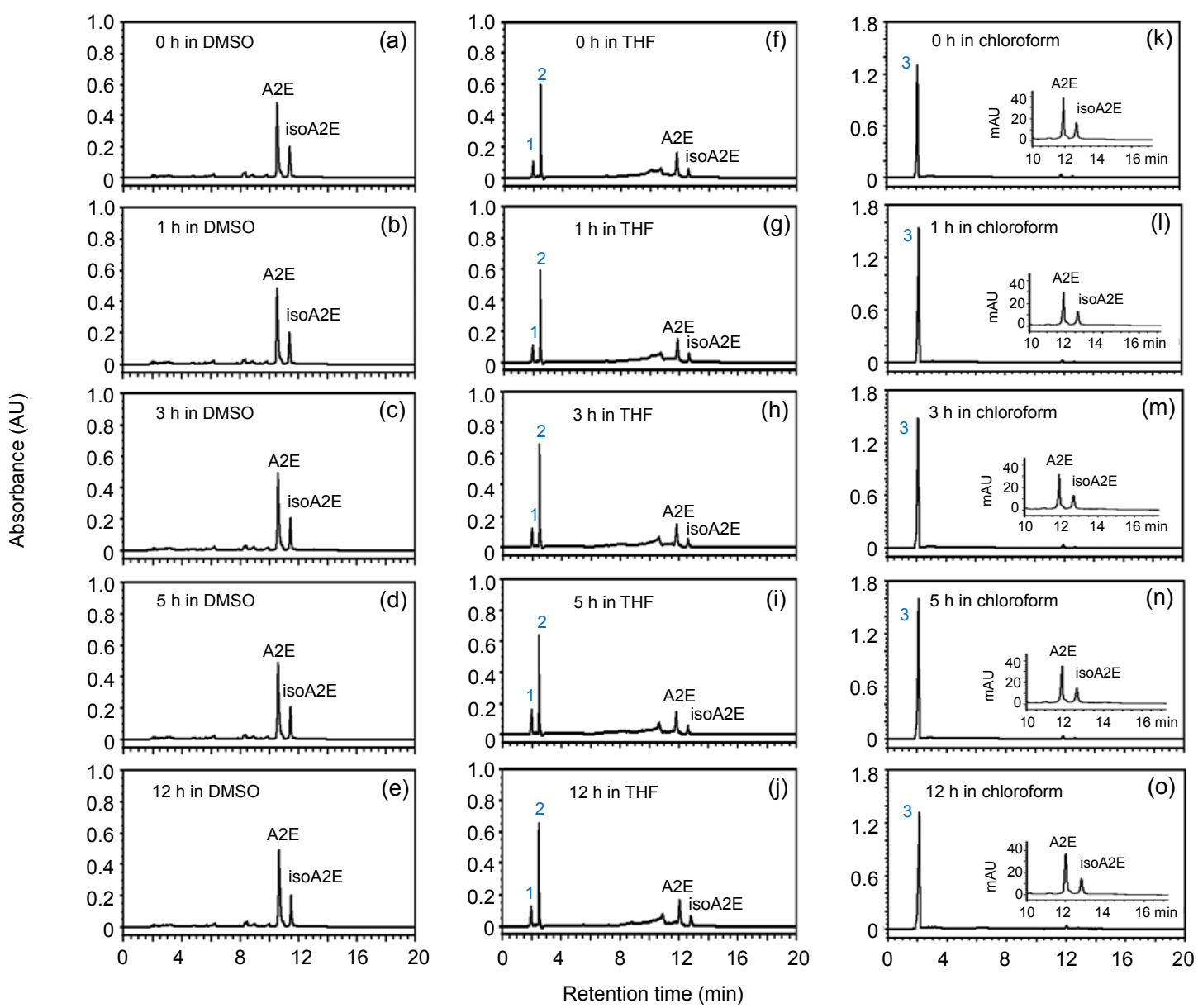

Fig. 2 Chromatographic analysis of A2E incubated in DMSO (a-e), THF (f-j), and chloroform (k-o)

Representative reverse-phase HPLC chromatograms of A2E were generated after exposure to organic solvents for 0 ( $a, f$, k), $1(\mathrm{~b}, \mathrm{~g}, \mathrm{l}), 3(\mathrm{c}, \mathrm{h}, \mathrm{m}), 5(\mathrm{~d}, \mathrm{i}, \mathrm{n})$, and $12 \mathrm{~h}(\mathrm{e}, \mathrm{j}, \mathrm{o})$. These final solutions $(300 \mu \mathrm{mol} / \mathrm{L})$ were analyzed by reverse-phase HPLC on an Atlantis dC18 column, monitoring at $430 \mathrm{~nm}$. AU: absorbance units; mAU: milli-absorbance units. Peaks 1-3, eluted much earlier than the A2E peak, were formed from incubations of A2E in THF and chloroform. Insets in (k-o) are chromatograms expanded between retention time of 10-16 $\mathrm{min}$ 
was added. For THF treatment, one symmetrical peak, eluted slightly earlier than the ATR-dimer peak, absorbed at 290 and $430 \mathrm{~nm}$, which was accordant with the absorbance maxima of ATR-dimer. In contrast, incubation of ATR-dimer in chloroform gave rise to two irregular peaks that were eluted slightly earlier than the ATR-dimer peak during $0-5 \mathrm{~h}$ (Figs. 3p-3s). These two peaks were converted into a broad peak after $12 \mathrm{~h}$ incubation (Fig. 3t).

\subsection{Quantification of pigments in organic solvents}

Quantification of A2E and ATR-dimer incubated with organic solvents in one or three independent experiments revealed that levels of these two adducts were significantly decreased by THF and chloroform (Fig. 7), but remained invariant in $\mathrm{MeOH}$ (Figs. 4f and 6f). In addition, there was no loss of ATR-dimer in cyclohexane or EtOH (Figs. 61 and 7b), whereas the mixture of $\mathrm{A} 2 \mathrm{E}$ with $\mathrm{EtOH}$ caused a significant loss of this fluorophore (Fig. 41).

\subsection{Extraction and quantification of pigments in mouse eyecups}

We designed process II to extract and quantify ATR-dimer, and processes III and IV for determination of A2E in eyecups of C57BL/6 mice. Examination of the extracts from posterior eyecups dissected from mice (aged 8 months) indicated that the amounts of ATR-dimer in each eyecup detected by process II were much higher than those detected by process I (Fig. 8a). As to A2E levels per eyecup, process III, like process IV, released more A2E than process I (Fig. 8b). Elevated levels of A2E and ATR-dimer per eyecup by processes II-IV reflected that these newly designed processes were more effective than process I.

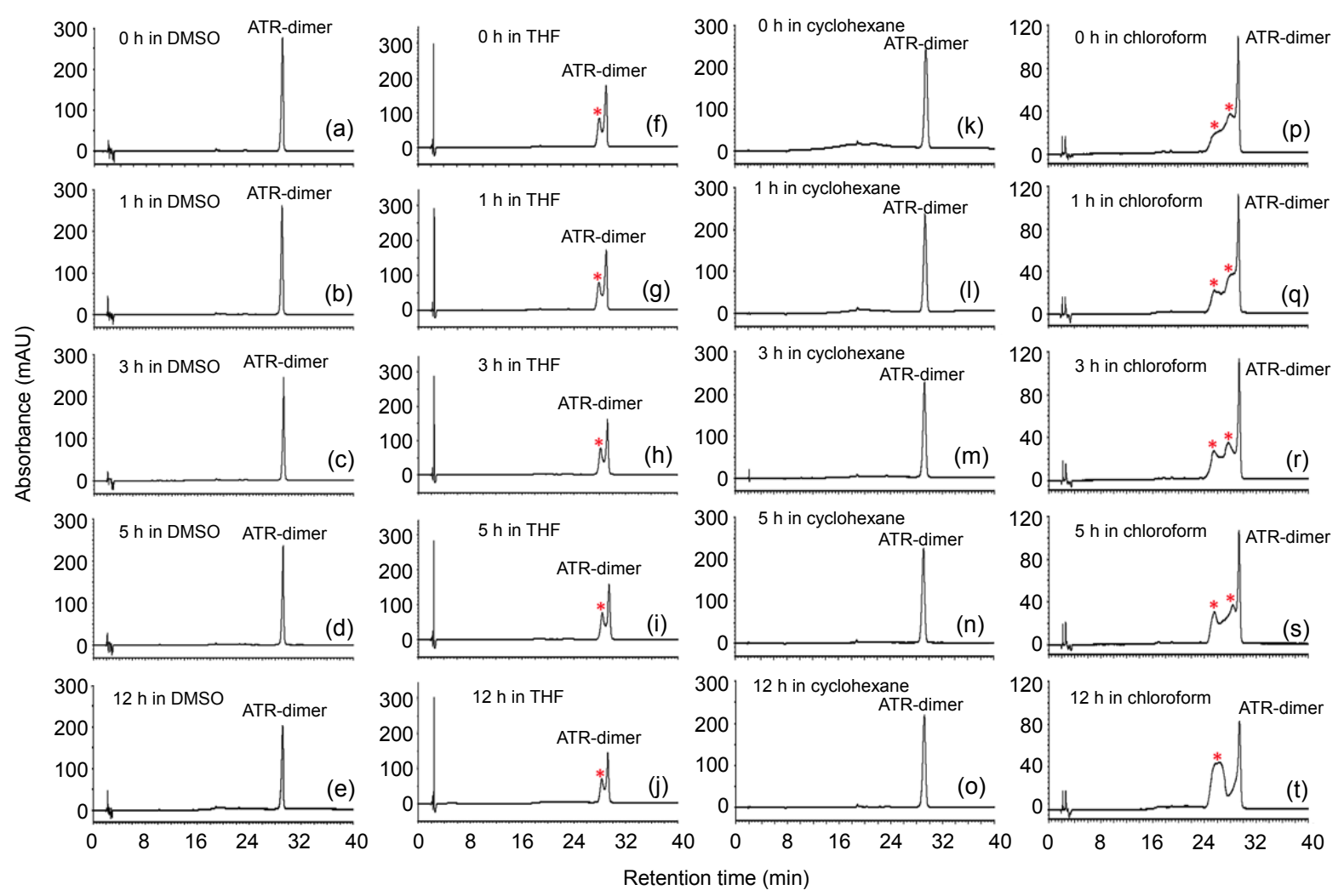

Fig. 3 Chromatographic analysis of ATR-dimer incubated in DMSO (a-e), THF (f-j), cyclohexane (k-o), and chloroform (p-t)

Representative reverse-phase HPLC chromatograms of ATR-dimer were obtained after exposure to organic solvents for 0 $(\mathrm{a}, \mathrm{f}, \mathrm{k}, \mathrm{p}), 1(\mathrm{~b}, \mathrm{~g}, \mathrm{l}, \mathrm{q}), 3(\mathrm{c}, \mathrm{h}, \mathrm{m}, \mathrm{r}), 5(\mathrm{~d}, \mathrm{i}, \mathrm{n}, \mathrm{s})$, and $12 \mathrm{~h}(\mathrm{e}, \mathrm{j}, \mathrm{o}, \mathrm{t})$. These final solutions $(300 \mu \mathrm{mol} / \mathrm{L})$ were analyzed by reverse-phase HPLC on an Atlantis dC18 column, monitoring at $430 \mathrm{~nm}$. mAU: milli-absorbance units. The asterisks $\left({ }^{*}\right)$ indicated additional components that were generated from the incubation of ATR-dimer with THF and chloroform and were eluted in front of ATR-dimer 

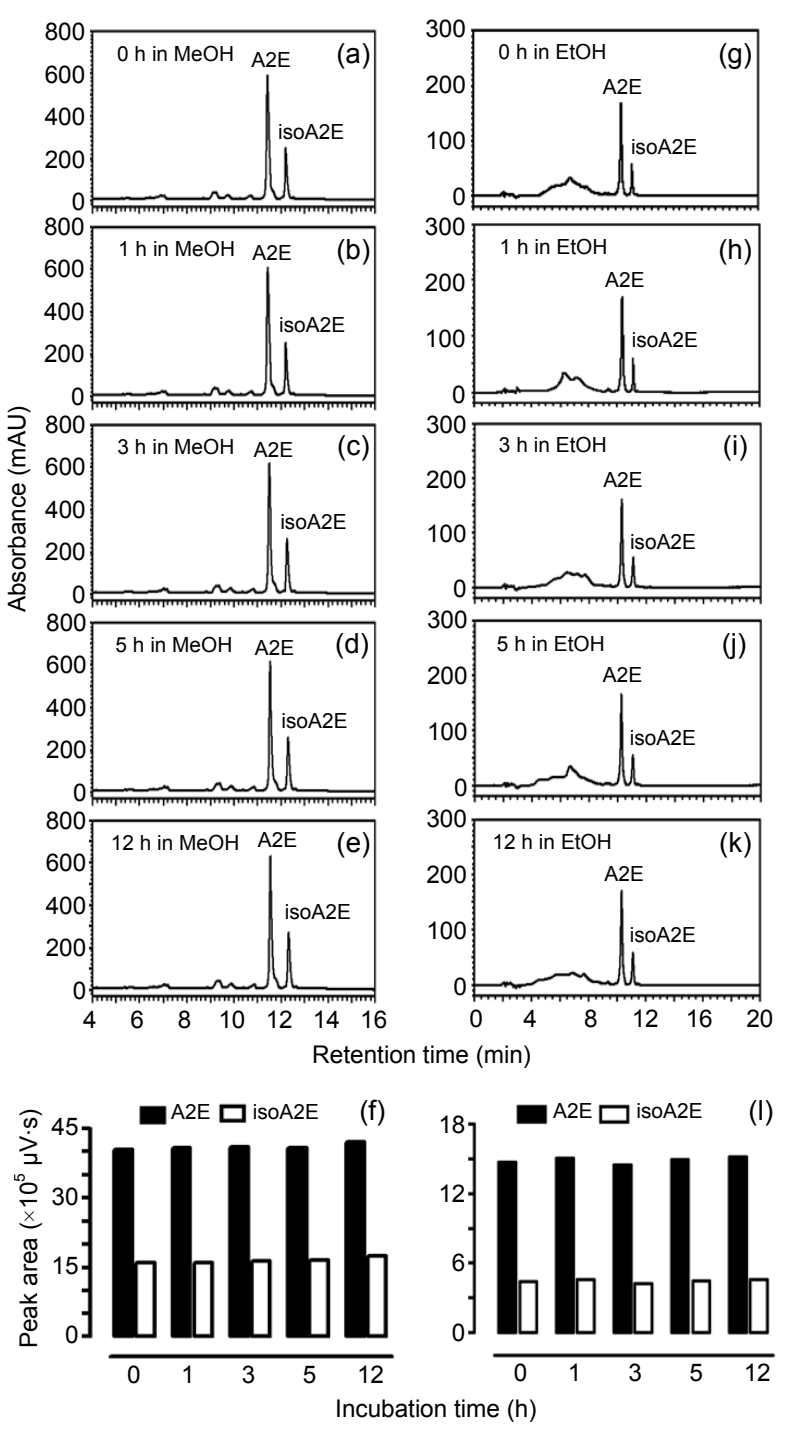

Fig. 4 Chromatographic analysis of $\mathrm{A2E}$ incubated in $\mathrm{MeOH}(\mathrm{a}-\mathrm{f})$ and EtOH (g-l)

Reverse-phase HPLC chromatograms of A2E were generated when exposed to $\mathrm{MeOH}(\mathrm{a}-\mathrm{e})$ and $\mathrm{EtOH}(\mathrm{g}-\mathrm{k})$ for $0(\mathrm{a}$, g), 1 (b, h), 3 (c, i), $5(\mathrm{~d}, \mathrm{j})$, and $12 \mathrm{~h} \mathrm{(e,} \mathrm{k).} \mathrm{These} \mathrm{final}$ solutions $(300 \mu \mathrm{mol} / \mathrm{L})$ were analyzed by reverse-phase HPLC on an Atlantis dC18 column, monitoring at $430 \mathrm{~nm}$. mAU: milli-absorbance units. $\mathrm{A} 2 \mathrm{E}$ and isoA2E were quantified after incubation in $\mathrm{MeOH}$ (f) and $\mathrm{EtOH}$ (l) for 0-12 h. Chromatographic peak areas were measured and calculated using Empower ${ }^{\mathbb{R}} 3$ software
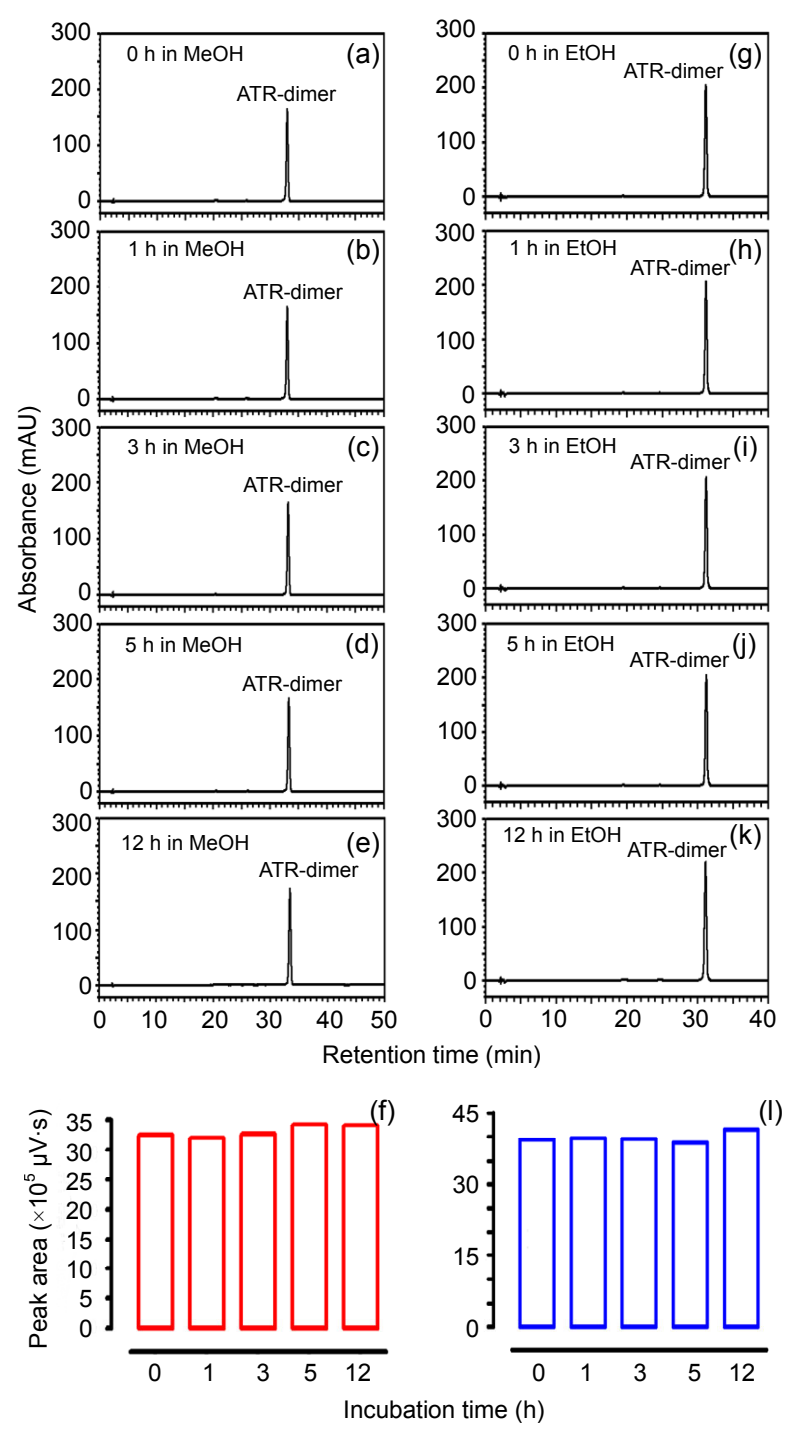

Fig. 6 Chromatographic analysis of ATR-dimer incubated in $\mathrm{MeOH}(\mathrm{a}-\mathrm{f})$ and $\mathrm{EtOH}(\mathrm{g}-\mathrm{I})$

Reverse-phase HPLC chromatograms of ATR-dimer were obtained after exposure to $\mathrm{MeOH}(\mathrm{a}-\mathrm{e})$ and $\mathrm{EtOH}(\mathrm{g}-\mathrm{k})$ for $0(\mathrm{a}, \mathrm{g}), 1(\mathrm{~b}, \mathrm{~h}), 3(\mathrm{c}, \mathrm{i}), 5(\mathrm{~d}, \mathrm{j})$, and $12 \mathrm{~h}(\mathrm{e}, \mathrm{k})$. These final solutions $(300 \mu \mathrm{mol} / \mathrm{L})$ were analyzed by reverse-phase HPLC on an Atlantis dC18 column, monitoring at $430 \mathrm{~nm}$. mAU: milli-absorbance units. ATR-dimer was quantified after incubation in $\mathrm{MeOH}$ (f) and EtOH (l) for 0-12 h. Chromatographic peak areas were measured and calculated using Empower ${ }^{\circledR} 3$ software
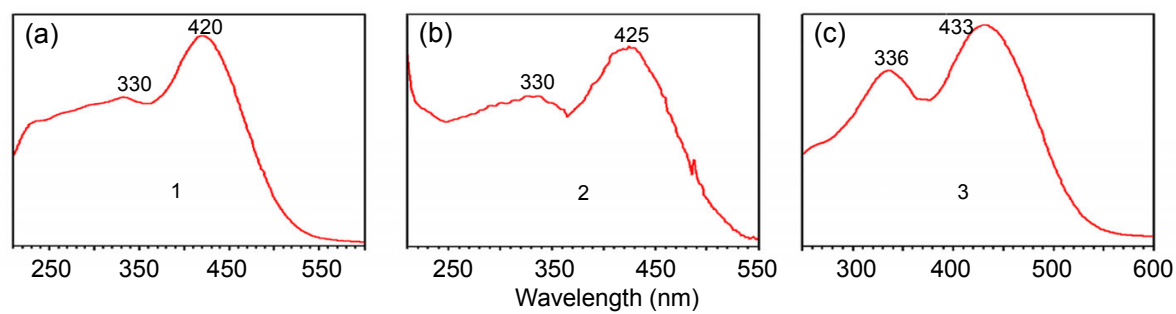

Fig. 5 UV-visible absorbance spectra of peaks 1-3

A2E was incubated in THF to release peaks 1 (a) and 2 (b), and in chloroform to yield peak 3 (c) 

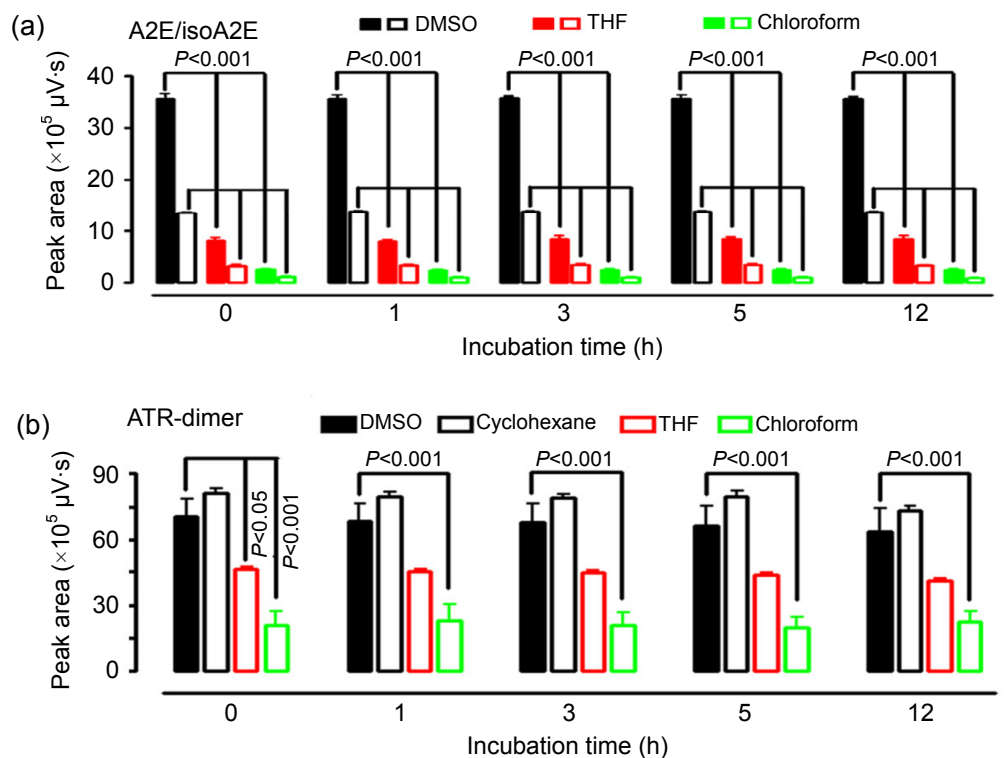

Fig. 7 HPLC quantification of A2E (a) and ATR-dimer (b) after incubation in organic solvents

Incubation time was $0,1,3,5$, and $12 \mathrm{~h}$. Chromatographic peak areas were measured and expressed as mean \pm standard error of the mean (SEM) of three independent experiments

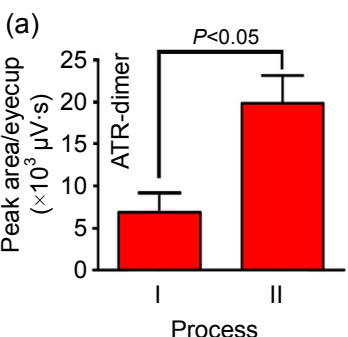

(b)

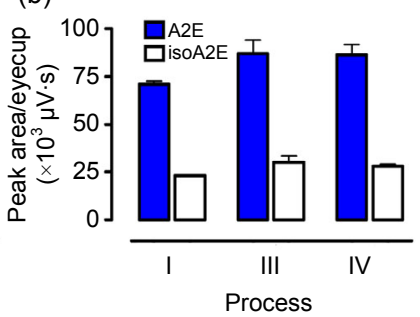

Fig. 8 HPLC quantification of ATR-dimer (a) and A2E (b) in eyecups of C57BL/6 mice

These two pigments in eyecups of 8-month-old mice were obtained and quantified by processes I-IV. The values are expressed as mean \pm standard error of the mean (SEM) of two samples (4-6 eyecups/sample)

\section{Discussion}

In the development of therapeutic approaches to cure Stargardt's disease and AMD, much attention is being given to therapies that reduce the formation of RPE cell lipofuscin constituents (Sieving et al., 2001; Radu et al., 2003; 2005; Maiti et al., 2006). These strategies include gene therapies based on adenoassociated virus-mediated and lentiviral-mediated delivery of the wild-type gene (Allocca et al., 2008), and systemic administration of compounds that limit the retinoid cycle (Kong et al., 2008). A2E and ATR-dimer serve as the therapeutic targets and are measured in vivo for the evaluation of remedial effects in all of these preclinical studies. Organic solvents function as a necessary vehicle for obtaining and quantifying these two compounds in the eyes. Based on the foregoing results, we demonstrated that some organic solvents caused distinct alteration of A2E and ATR-dimer. However, we noted that levels of the remaining pigments were not significantly different after incubation for $0-12 \mathrm{~h}$, indicating the presence of an equilibrium between altered pigments and unaffected materials in these organic solvents. In experiments, we also observed that the low solubility of ATR-dimer in DMSO was a barrier to making a stock solution with DMSO. To solve this problem, a small amount of cyclohexane was firstly added to dissolve ATR-dimer, followed by the addition of DMSO. The high boiling-point of DMSO, together with the low boiling-point of cyclohexane, facilitates the removal of cyclohexane by a rotary evaporator. Given that ATR-dimer is poorly soluble in $\mathrm{MeOH}$, processes III and IV are not applicable to the determination of this pigment in the eyes. Understanding the effects of organic solvents on lipofuscin constituents will provide insights into the proper usage of these important fluorophores and facilitate the establishment of rational processes for measuring each endogenous pigment.

\section{Compliance with ethics guidelines}

Qiu-xia JIN, Xin-ran DONG, Jing-meng CHEN, Ke YAO, and Ya-lin WU declare that they have no conflicts of interest.

All institutional and national guidelines for the care and use of laboratory animals were followed. 


\section{References}

Ahn, J., Wong, J.T., Molday, R.S., 2000. The effect of lipid environment and retinoids on the ATPase activity of $\mathrm{ABCR}$, the photoreceptor $\mathrm{ABC}$ transporter responsible for Stargardt macular dystrophy. J. Biol. Chem., 275(27): 20399-20405. [doi:10.1074/jbc.M000555200]

Allikmets, R., Singh, N., Sun, H., et al., 1997. A photoreceptor cell-specific ATP-binding transporter gene $(A B C R)$ is mutated in recessive Stargardt macular dystrophy. Nat. Genet., 15(3):236-246. [doi:10.1038/ng0397-236]

Allocca, M., Doria, M., Petrillo, M., et al., 2008. Serotypedependent packaging of large genes in adeno-associated viral vectors results in effective gene delivery in mice. $J$. Clin. Invest., 118(5):1955-1964. [doi:10.1172/JCI34316]

Ben-Shabat, S., Parish, C.A., Vollmer, H.R., et al., 2002. Biosynthetic studies of A2E, a major fluorophore of retinal pigment epithelial lipofuscin. J. Biol. Chem., 277(9): 7183-7190. [doi:10.1074/jbc.M108981200]

Chrispell, J.D., Feathers, K.L., Kane, M.A., et al., 2009. Rdh12 activity and effects on retinoid processing in the murine retina. J. Biol. Chem., 284(32):21468-21477. [doi:10. 1074/jbc.M109.020966]

Fishkin, N.E., Sparrow, J.R., Allikmets, R., et al., 2005. Isolation and characterization of a retinal pigment epithelial cell fluorophore: an all-trans-retinal dimer conjugate. PNAS, 102(20):7091-7096. [doi:10.1073/pnas.0501266102]

Holz, F.G., Schutt, F., Kopitz, J., et al., 1999. Inhibition of lysosomal degradative functions in RPE cells by a retinoid component of lipofuscin. Invest. Ophthalmol. Vis. Sci., 40(3):737-743.

Kim, S., Jang, Y., Jockusch, S., et al., 2007. The all-transretinal dimer series of lipofuscin pigments in retinal pigment epithelial cells in a recessive Stargardt disease model. PNAS, 104(49):19273-19278. [doi:10.1073/pnas. 0708714104]

Kong, J., Kim, S.R., Binley, K., et al., 2008. Correction of the disease phenotype in the mouse model of Stargardt disease by lentiviral gene therapy. Gene Ther., 15(19): 1311-1320. [doi:10.1038/gt.2008.78]

Liu, J., Itagaki, Y., Ben-Shabat, S., et al., 2000. The biosynthesis of A2E, a fluorophore of aging retina, involves the formation of the precursor, A2-PE, in the photoreceptor outer segment membrane. J. Biol. Chem., 275(38): 29354-29360. [doi:10.1074/jbc.M910191199]

Maeda, A., Maeda, T., Sun, W., et al., 2007. Redundant and unique roles of retinol dehydrogenases in the mouse retina. PNAS, 104(49):19565-19570. [doi:10.1073/pnas. 0707477104]

Maiti, P., Kong, J., Kim, S.R., et al., 2006. Small molecule RPE65 antagonists limit the visual cycle and prevent lipofuscin formation. Biochemistry, 45(3):852-860. [doi: 10.1021/bi0518545]

Parish, C.A., Hashimoto, M., Nakanishi, K., et al., 1998. Isolation and one-step preparation of $\mathrm{A} 2 \mathrm{E}$ and iso-A2E, fluorophores from human retinal pigment epithelium.
PNAS, 95(25):14609-14613. [doi:10.1073/pnas.95.25. 14609]

Radu, R.A., Mata, N.L., Nusinowitz, S., et al., 2003. Treatment with isotretinoin inhibits lipofuscin accumulation in a mouse model of recessive Stargardt's macular degeneration. PNAS, 100(8):4742-4747. [doi:10.1073/pnas.0737 855100]

Radu, R.A., Han, Y., Bui, T.V., et al., 2005. Reductions in serum vitamin A arrest accumulation of toxic retinal fluorophores: a potential therapy for treatment of lipofuscin-based retinal diseases. Invest. Ophthalmol. Vis. Sci., 46(12):4393-4401. [doi:10.1167/iovs.05-0820]

Shroyer, N.F., Lewis, R.A., Allikmets, R., et al., 1999. The rod photoreceptor ATP-binding cassette transporter gene, $A B C R$, and retinal disease: from monogenic to multifactorial. Vision Res., 39(15):2537-2544. [doi:10.1016/ S0042-6989(99)00037-1]

Sieving, P.A., Chaudhry, P., Kondo, M., et al., 2001. Inhibition of the visual cycle in vivo by 13-cis-retinoic acid protects from light damage and provides a mechanism for night blindness in isotretinoin therapy. PNAS, 98(4):1835-1840. [doi:10.1073/pnas.98.4.1835]

Sparrow, J.R., Boulton, M., 2005. RPE lipofuscin and its role in retinal pathobiology. Exp. Eye Res., 80(5):595-606. [doi:10.1016/j.exer.2005.01.007]

Sparrow, J.R., Parish, C.A., Hashimoto, M., et al., 1999. A2E, a lipofuscin fluorophore, in human retinal pigmented epithelial cells in culture. Invest. Ophthalmol. Vis. Sci., 40(12):2988-2995.

Sparrow, J.R., Nakanishi, K., Parish, C.A., 2000. The lipofuscin fluorophore A2E mediates blue light-induced damage to retinal pigmented epithelial cells. Invest. Ophthalmol. Vis. Sci., 41(7):1981-1989.

Sparrow, J.R., Vollmer, H.R., Zhou, J., et al., 2003. A2E-epoxides damage DNA in retinal pigment epithelial cells. J. Biol. Chem., 278(20):18207-18213. [doi:10. 1074/jbc.M300457200]

Sparrow, J.R., Kim, S.R., Cuervo, A.M., et al., 2008. A2E, a pigment of RPE lipofuscin is generated from the precursor A2PE by a lysosomal enzyme activity. In: Anderson, R.E., LaVail, M.M., Hollyfield, J.G. (Eds.), Recent Advances in Retinal Degeneration. Advances in Experimental Medicine and Biology. Volume 613, Springer New York, p.393-398. [doi:10.1007/978-0-387-74904-4_46]

Sun, H., Molday, R.S., Nathans, J., 1999. Retinal stimulates ATP hydrolysis by purified and reconstituted ABCR, the photoreceptor-specific ATP-binding cassette transporter responsible for Stargardt disease. J. Biol. Chem., 274(12): 8269-8281. [doi:10.1074/jbc.274.12.8269]

Suter, M., Reme, C., Grimm, C., et al., 2000. Age-related macular degeneration. The lipofusion component $N$-retinyl$N$-retinylidene ethanolamine detaches proapoptotic proteins from mitochondria and induces apoptosis in mammalian retinal pigment epithelial cells. J. Biol. Chem., 275(50):39625-39630. [doi:10.1074/jbc.M007049200] 
Vasireddy, V., Jablonski, M., Khan, N., et al., 2009. Elovl4 5-bp deletion knock-in mouse model for Stargardt-like macular degeneration demonstrates accumulation of ELOVL4 and lipofusin. Exp. Eye Res., 89(6):905-912. [doi:10.1016/j.exer.2009.07.021]

Weng, J., Mata, N.L., Azarian, S.M., et al., 1999. Insights into the function of Rim protein in photoreceptors and etiology of Stargardt's disease from the phenotype in $a b c r$ knockout mice. Cell, 98(1):13-23. [doi:10.1016/S00928674(00)80602-9]

Wielgus, A.R., Chignell, C.F., Ceger, P., et al., 2010. Comparison of A2E cytotoxicity and phototoxicity with all-trans-retinal in human retinal pigment epithelial cells. Photochem. Photobiol., 86(4):781-791. [doi:10.1111/ j.1751-1097.2010.00750.x]
Wu, L., Nagasaki, T., Sparrow, J.R., 2010. Photoreceptor cell degeneration in $\mathrm{Abcr}^{-/-}$mice. In: Anderson, R.E., Hollyfield, J.G., LaVail, M.M. (Eds.), Retinal Degenerative Diseases. Laboratory and Therapeutic Investigations. Advances in Experimental Medicine and Biology. Volume 664, Springer New York, p.533-539. [doi:10.1007/ 978-1-4419-1399-9_61]

Wu, Y., Li, J., Yao, K., 2013. Structures and biogenetic analysis of lipofuscin bis-retinoids. J. Zhejiang Univ.-Sci. B (Biomed. \& Biotechnol.), 14(9):763-773. [doi:10.1631/ jzus.B1300051]

Yamamoto, K., Yoon, K.D., Ueda, K., et al., 2011. A novel bisretinoid of retina is an adduct on glycerophosphoethanolamine. Invest. Ophthalmol. Vis. Sci., 52(12):90849090. [doi:10.1167/iovs.11-8632]

\section{中文概要：}

\section{本文标题: 有机溶剂对两种视网膜色素上皮脂褐质苂光色素的影响}

Effects of organic solvents on two retinal pigment epithelial lipofuscin fluorophores, A2E and all-trans-retinal dimer

研究目的：减缓 Stargardt 和年龄相关性黄斑变性患者视力损失的基因和药物疗法正处于发展中, 然而为 了评价对实验小鼠的治疗效果, 有机溶剂是获取及定量小鼠后眼罩脂褐质色素必需的载体。 本工作报道了有机溶剂对 $N$-亚视黄基- $N$-视黄基乙醇胺（A2E）和全反式视黄醛二聚体两种重 要脂褐质色素的影响以及从体内获取和定量它们的优化方法。

创新要点: 本文阐释了二甲亚砜、甲醇、氯仿、四氢呋喃、环己烷和乙醇对 $\mathrm{A} 2 \mathrm{E}$ 和全反式视黄醛二聚体 两种脂褐质色素的影响, 并且优化了它们的体内获取及定量程序。

研究方法: 采用高效液相色谱技术分析 A2E 和全反式视黄醛二聚体溶液以及 C $57 \mathrm{BL} / 6$ 小鼠后眼罩浸亳。

重要结论: 氯仿和四氢呋喃能够改变 $\mathrm{A} 2 \mathrm{E}$ 和全反式视黄醛二聚体, 但是它们在二甲亚砜和甲醇中是稳定 的; 环己烷和乙醇不影响全反式视黄醛二聚体, 然而 A2E 在乙醇中不稳定, 在环己烷中溶解 度很低。脂褐质元素体内获取及定量的优化方法能够释放出更多的全反式视黄醛二聚体和 $\mathrm{A} 2 \mathrm{E}$ 。理解有机溶剂对脂褐质色素的影响将为正确使用这些色素提供洞察力, 也可促进建立 每个内源性色素测量的合理方法。

关键词组: 脂褐质; 类视色素二聚体; 有机溶剂; 视网膜色素上皮; 苂光色素 